\title{
Representações sociais de professores sobre a qualidade de vida dos seus alunos
}

\section{Social representations on quality of life in the school scenario}

\section{Luciene Alves Miguez Naiff*}

Universidade Federal Rural do Rio de Janeiro - UFRRJ, Seropédica, Rio de Janeiro, Brasil

\section{Denis Giovani Monteiro Naiff**}

Universidade Federal Rural do Rio de Janeiro - UFRRJ, Seropédica, Rio de Janeiro, Brasil

\author{
Alcina Maria Testa Braz*** \\ Universidade Salgado de Oliveira - UNIVERSO, São Gonçalo, Rio de Janeiro, Brasil
}

\begin{abstract}
RESUMO
O objetivo do presente estudo foi identificar as representações sociais de 110 professores de escolas municipais, localizadas em comunidades que vivenciam vulnerabilidade econômica acerca da qualidade de vida de seus alunos. As representações sociais que produzimos são filtros que nos auxiliam no entendimento do mundo e orientam nossos comportamentos. Foi utilizada a abordagem estrutural das representações sociais que argumenta a favor da existência de um núcleo central e um sistema periférico que organiza hierarquicamente os elementos representacionais. Os elementos mais centrais encontrados foram: saúde, educação, família e alimentação que correspondem às principais carências vivenciadas por seus alunos. Em segundo lugar aparecem os elementos lazer, paz e moradia que também são identificados como deficitários na vida dos alunos pela visão dos professores. Os professores percebem em seus alunos carências de itens básicos que compõem a definição de qualidade de vida e creditam a escola um importante papel na reversão desse quadro.

Palavras-chaves: Representações sociais, Professores, Qualidade de vida.
\end{abstract}

\begin{abstract}
The aim of this study was to identify the views on social representations presented by 110 teachers. All interviewees work at municipal schools located at low income communities where life quality is deeply compromised. The social representations can be seen as 'filters' that help us comprehend our surroundings but also orientate inter-personal relationships. The proposal was to identify central and peripheral elements around the term quality of life. Therefore, according to these teachers the central elements were: health, education, family and subsistence and it corresponds to how teachers perceive all the vulnerabilities faced by their students. As peripheral elements appeared the following terms leisure, peace and housing. Teachers perceive their students as lacking basic items
\end{abstract}


that make up the definition of quality of life and credit the school an important role in reversing this situation.

Keywords: Social representations, Teachers, Quality of life

\section{I ntrodução}

A presente pesquisa buscou identificar as representações sociais de professores de escolas públicas acerca da noção de qualidade de vida de seus alunos. Foram escolhidas escolas públicas localizadas em comunidades com altos índices de vulnerabilidade econômica na Região Metropolitana do Estado do Rio de Janeiro. Segundo o IBGE, esses espaços são também chamados de aglomerados subnormais ou, como ficou conhecido no discurso reinante, "favelas" (IBGE, 2000). As "favelas" urbanas chamam a atenção pelo seu alto grau de pobreza e desigualdade, e pelo recorrente desrespeito aos direitos sociais, apesar da proximidade com o desenvolvimento das cidades na qual estão instaladas.

A interface entre educação e pobreza vem sendo alvo de numerosos estudos, tanto do ponto de vista das consequências positivas da escolaridade na inserção social, quanto dos malefícios de sua ausência (NAIFF; SÁ, 2008; NAIFF; NAIFF, 2008). O Observatório de Políticas Urbanas e Gestão Municipal, a partir de uma contagem populacional de 1996 realizada pelo IBGE, comparou a distribuição por escolaridade entre a população residente e a não residente em favelas, analisando como variável as zonas geográficas da cidade do Rio de Janeiro. Na zona sul, área com maiores indicadores sócioeconômicos, 33,7\% dos moradores de favelas não tinham instrução nenhuma e $40 \%$ não haviam completado o primeiro segmento do ensino fundamental, ou seja, até o quinto ano; enquanto que entre a população que não morava em favelas, apenas $7,2 \%$ não haviam completado esse primeiro segmento do ensino fundamental. Por outro lado, 38,9\% tinham mais de 12 anos de estudo completos. Os dados foram similares na zona norte da cidade, com 35,6\% dos moradores de favelas não possuindo nenhuma instrução e $39,9 \%$ não haviam completado o primeiro segmento do ensino fundamental. Entre os não moradores das favelas, 39,5\% apresentavam mais de 12 anos de estudo completos (Prefeitura do Rio de Janeiro, 2001).

Desta forma, os dados supracitados reafirmam para a educação como um dos principais fatores que diferenciam os grupos sociais em relação ao seu local de moradia. O pano de fundo dessa discussão é a pobreza. Segundo Naiff e Sá (2008), a escola aparece nas histórias de vida de moradores de comunidades carentes em um discurso que a relaciona com possibilidades de mudanças de vida altamente positivada. Paradoxalmente, percebemos que a escola não faz parte do cotidiano desse grupo, ficando de fora também de seus projetos 
de vida. Esse fato está relacionado a motivos variados que vão desde a evasão ainda cedo pela necessidade de geração de renda e gravidez precoce no estrato feminino, até o desinteresse pela falta de vinculação das expectativas de futuro com a aquisição da escolaridade (NAIFF; SÁ, 2008; NAIFF; NAIFF, 2008). Targino (1991), por sua vez, ressalta que o direito à educação afeta o status da cidadania, se entendido como o direito do cidadão adulto ter sido educado e informado.

Assim, a proposta de uma pesquisa que identifique as representações sociais dos professores que atuam em comunidades economicamente vulneráveis acerca da qualidade de vida de seus alunos pode oferecer significativas contribuições no entendimento das relações interpessoais desenvolvidas no ambiente escolar. Isto porque, pelo referencial teórico adotado, os educadores produzem representações sociais no intuito de se familiarizar com fenômenos sociais que os afetam e, em última análise, utilizar esse conhecimento para direcionar suas ações (MOSCOVICl, 1979).

\section{Qualidade de vida e cidadania}

A noção de qualidade de vida é polissêmica, como nos orienta Minayo, Hartz, e Buzz (2000), já que nos direciona a tudo que uma sociedade elege enquanto padrão de conforto, dignidade e cidadania. Portanto, falando de qualidade de vida falamos, entre outras coisas, de cidadania. Essa relação direta entre os conceitos de qualidade de vida e cidadania merece uma maior aproximação.

Cidadão é, segundo Ferreira (2009, p.45), “o indivíduo no gozo dos direitos civis e políticos de um Estado, ou no desempenho de seus deveres para com este". No Brasil, desde a Constituição de 1934 e reforçada e ampliada na Constituição de 1988, o Estado é responsável pela proteção aos direitos sociais que são assim definidos no artigo 60 de nossa última Constituição: "acesso a educação, a saúde, o trabalho, a moradia, o lazer, a segurança, a previdência social, a proteção à maternidade e à infância e a assistência aos desamparados". Os direitos sociais devem atingir todos os cidadãos, mas são mais fortemente demandados ao Estado pelos grupos sociais menos favorecidos economicamente. Segundo Silva (1993, apud VELLOSO, 2003), nesse caso os direitos sociais são:

Prestações positivas proporcionadas pelo Estado direta ou indiretamente, anunciadas em normas constitucionais, que possibilitam melhores condições de vida aos mais fracos, direitos que tendem a realizar a equalização de situações sociais desiguais (p.289). 
Freire (1992) ressalta a questão do contexto relacional afirmando que:

\begin{abstract}
A história não é feita de indivíduos, ela é socialmente feita por nós todos e cidadania é o máximo de uma presença critica no mundo da história por ela narrada. A cidadania não é apenas o fato de ser um cidadão que vota. (...) O conceito de cidadania vem casado com o conceito de participação, de ingerência nos destinos históricos e sociais do contexto onde a gente está (p.129).
\end{abstract}

Em uma concepção histórica do conceito feita por Marshall (1967) há três elementos constitutivos dos direitos de cidadania: (a) os direitos civis representam os direitos do indivíduo na sociedade e referem-se à liberdade individual; (b) os direitos políticos são conquistados a partir dos direitos civis assegurados e ampliados pelo direito de participar do exercício do poder, mediante o voto ou investido de autoridade, como representante eleito; (c) os direitos sociais, isto é, a vivência de bem-estar social e econômico, de acordo com padrões que garantam a dignidade humana naquele contexto social.

No que se refere ao conceito de "qualidade de vida", esta é uma noção construída por uma coletividade e se baseia no contexto histórico, cultural e social a que está relacionada. Isto quer dizer que obedece às necessidades de cada uma das esferas supracitadas, quais sejam: ao tempo histórico em que é definida; a cultura valorizada nesse momento temporal e ao grupo social a que se refere. Januzzi (2002) orienta acerca dessa dificuldade conceitual, na medida em que esse tema é oriundo de diferentes fontes de conhecimento e tem caráter mutante por estar condicionado a um consenso social que pode variar. Normalmente, aquilo que é eleito como padrão de qualidade de vida de um grupo social é revisto dependendo do ponto de referência.

A busca por uma melhor qualidade de vida tem sido uma constante nas sociedades. Isto tem gerado tentativas de se estabelecer valores para o nível de qualidade de vida, a partir de indicadores econômicos, taxas de natalidade, mortalidade infantil, esperança de vida, alfabetização, consumo alimentar, prática de atividade física, entre outros aspectos que traduzem sua complexidade, enredada que está com questões de ordem social, como meio-ambiente, educação, segurança e promoção da saúde (DEVIDE, 2002, p.65).

Atualmente o quesito saúde tem uma importância superdimensionada na definiç̧ão de qualidade de vida (MINAYO; HARTZ; BUSS, 2000; DEVIDE, 2002). Existe, inclusive, uma definição própria oferecida pela Organização Mundial de Saúde (OMS, 1996) que serve de indexador para formulação de políticas públicas. Nesse sentido, a qualidade de vida torna-se "a percepção do indivíduo de sua posição 
na vida, no contexto da cultura e sistemas de valores nos quais vive e em relação aos seus objetivos, expectativas, padrões e preocupações" (WHOQOL, 1995, p. 1403).

Segundo Albuquerque e França (1998), a concepção de saúde está tão intimamente ligada à percepção de bem-estar que incorpora não apenas o aspecto biológico, mas também, com igual força, os aspectos psicológicos e sociais.

Em síntese, qualidade de vida diz respeito ao atendimento das necessidades mais básicas e objetivas àquelas vistas como subjetivas que vão desde os elementos que garantam a sobrevivência até os desejos e expectativas a serem atingidas. Quem determina e escalona em ordem de importância os elementos que compõem a qualidade de vida de um grupo é o consenso histórico e socialmente situado (JANUZZI, 2002; ROCHA; FELL, 2004).

No presente trabalho, propôs-se a discussão acerca do conceito de qualidade de vida em um contexto específico que é a escola. A educação é atualmente um dos grandes eixos em que se encerram as discussões sobre cidadania e inserção social. Nesse sentido, fornir o debate sobre qualidade de vida e educação com as representações sociais que os professores de escolas localizadas em aglomerados subnormais possuem sobre seus alunos podem favorecer 0 entendimento das relações interpessoais entre esses personagens que, vindos muitas vezes de contextos sociais diferentes, se encontram no universo escolar.

\section{Representações sociais, pobreza e educação: ampliando o diálogo}

Com base na perspectiva teórico-metodológica da teoria das representações sociais, apresentada por Serge Moscovici (1979, 2003), podemos afirmar que os grupos sociais produzem uma forma de conhecimento coletivamente consensuado e gerado em prol da familiarização dos fenômenos sociais a que estão expostos. Produzimos representações de fenômenos que são sociais, mas também as produzimos socialmente. Ou seja, os fenômenos que nos referimos estão implicados na necessidade de apropriação não de um indivíduo, mas de um grupo que produzirá um conhecimento que facilita a comunicação, fortalece a identidade, orienta e justifica as práticas sociais (Abric, 1994).

Nesse sentido, os grupos irão produzir representações sociais diferentes na medida em que os fenômenos sociais tiverem para eles importâncias variadas. O mesmo acontece com os professores. Essa categoria social possui peculiaridades que nos licencia a investigar suas representações sociais em relação principalmente a fenômenos oriundos de sua prática docente. 
Há na literatura várias pesquisas que exploram as representações sociais dos professores acerca de aspectos de seu cotidiano nas escolas (ALMEIDA; NAIFF, 2009; AZAMOR; NAIFF, 2008; NAIFF; SOARES; NAIFF; AZAMOR; ALMEIDA; SOUTO, 2010; WILSON; ALVES-MAZZOTI, 2004). O foco nesse estudo, no entanto, é no aluno, principal componente que define a relação do professor com a escola e com sua própria categoria profissional.

Pesquisa conduzida por Abramoway (2003) em 14 estados brasileiros encontrou na fala dos professores a importância atribuída à relação interpessoal na prática docente. Os dados apontaram que os professores relatavam construírem expectativas e se basearem muitas vezes em estereótipos dos alunos nas relações que se manifestavam no espaço escolar. Esse dado é corroborado por estudos de Alves-Mazzotti (2005) e Wilson e Alves-Mazzoti (2004) que apontam como os professores são influenciados nas interações sociais por suas percepções positivas ou negativas dos alunos. Isso significa dizer que, apesar da consciência atual do professorado em relação à importância de desenvolver habilidades relacionais, estas nem sempre envolvem aspectos facilitadores do aprendizado e da manutenção do aluno na escola (NAIFF; SOARES; NAIFF; AZAMOR; ALMEIDA; SOUTO, 2010).

O conceito de representação social designa uma forma de pensamento social e como define Jodelet (2001):

é uma forma de conhecimento, socialmente elaborada e partilhada, com objetivo prático, e que contribui para a construção de uma realidade comum a um conjunto social (p.22).

O arcabouço teórico da Teoria das Representações Sociais inclui as concepções originais desenvolvidas por Moscovici e as contribuições complementares desenvolvidas por Jodelet, Doise e Abric (Sá, 1996). Optamos, na presente pesquisas, pela abordagem estrutural proposta por Abric (1994) que apresenta os elementos componentes das representações sociais organizados em torno de dois sistemas: 0 sistema central e o sistema periférico. O sistema central, também chamado de núcleo central, possui a função geradora e organizadora da representação social, conferindo estabilidade a mesma. O sistema periférico agrega características mais instáveis e permeáveis. Com isso age como um dispositivo de defesa da representação frente a novos elementos desestabilizadores.

Ouvir os professores sobre como percebem a forma de viver de seus alunos, apóia a discussão a respeito da escola no cenário educacional contemporâneo. Muito se fala atualmente em inclusão social e nesse contexto a escola, em especial a escola pública, é apresentada como o lócus em que vários aspectos que compõem essa inclusão devem 
ter início. Políticas inclusivas e de ampliação do papel da escola e do professor precisam se calcar em estudos acerca da realidade em que as relações acontecem, e esse conhecimento não se dará sem que sejam ouvidos os principais atores envolvidos (POPKEWITZ; LINDBLAD, 2001; DEMO, 2007).

A Região Metropolitana do Rio de Janeiro possui aproximadamente 11 milhões de habitantes e mantém índices altos de desigualdade social entre os cidadãos dos municípios. É uma região com alta densidade populacional (concentra aproximadamente $73 \%$ de todos os habitantes do Estado) compreendendo 17 municípios, que tem como principais conseqüências: um índice de desigualdade de aproximadamente 15 vezes entre seus bairros mais ricos e os mais pobres, existência de comunidades carentes com até um milhão de habitantes; presença maciça do narcotráfico nestas comunidades com utilização de armamento pesado pelos traficantes e emprego de crianças e adolescentes nas linhas de frente do tráfico; falta de políticas públicas de inclusão e geração de renda para os jovens e falta de política de segurança (TOLEDO, 1998). É bem verdade que atualmente vemos mudanças de cenários desses espaços de exclusão. Na cidade do Rio de Janeiro vem sendo desenvolvida uma política de segurança baseada na instalação em comunidades menos favorecidas economicamente de UPPs- Unidades de Policia Pacificadora, que têm como objetivo extirpar a violência gerada pelo narcotráfico e pelas milícias, recuperar para o Estado territórios historicamente sob um regime de exclusão geográfica, permitindo dessa forma a urbanização e o desenvolvimento das comunidades. $O$ impacto dessa iniciativa vem sendo lido como positivo em se tratando de melhoria na sensação subjetiva de qualidade de vida, ainda que seja precoce uma análise mais aprofundada (PEREIRA, 2011).

Barros, Sales e Nogueira (2007) afirmam que "as favelas no Brasil, em pouco mais de cem anos de existência, passaram a ser um ícone de significações múltiplas: lugar perigoso, de higiene precária, habitat da malandragem, etc." (p.329). Naiff e Naiff (2005) corroboram esse argumento e ressaltam que os moradores das favelas passam a ser identificados a partir da moradia e que sofrem, em função disso, desqualificação social e preconceito. Portanto, ainda é real o preconceito fruto do desconhecimento acerca do que significa de fato a favela e seus moradores. A não familiaridade atinge os grupos sociais que não pertencem a esse contexto. Quando uma interação se faz necessária, como é o caso dos professores da presente pesquisa, - estranhamento resultante pode influenciar as relações interpessoais.

Os docentes brasileiros de escolas públicas são impactados com os desafios colocados no dia a dia que incluem dificuldades em se relacionarem com os alunos, baixos salários, falta de infra-estrutura adequada nas escolas e insegurança (ROCHA; FELL, 2004). Atuar 
diariamente em condições precárias demanda uma disposição maior do docente e gera desencanto com a profissão, com conseqüências desastrosas como o atual déficit de professores na rede pública que atinge aproximadamente 300 mil docentes em todo o Brasil (CBN, 2011). Essa evasão é gerada, tanto pelo abandono daqueles que já estavam exercendo a profissão quanto em relação a opção dos formados nas licenciaturas de não atuar na docência pública.

Twenge e King (2005) identificaram na percepção de qualidade de vida aspectos relacionais como mais importantes que profissionais. Em se tratando de uma profissão em que se relacionar faz parte das atividades profissionais, percebemos o quão importante é para o professor atuante conseguir um bom resultado relacional, além das boas médias de aprendizagem esperadas. Em recente pesquisa, professores de escolas públicas e privadas relacionaram o "domínio de turma" como um importante elemento definidor das habilidades de um bom docente. "Domínio de turma" se refere à capacidade do professor de manter um clima propício para o ensino e a aprendizagem do ponto de vista relacional (NAIFF; SOARES; NAIFF; AZAMOR; ALMEIDA; SOUTO, 2010).

Dos argumentos acima expostos vimos que a educação em um contexto de extrema pobreza e vulnerabilidade social se torna um grande desafio. No cotidiano escolar é o professor que fica em evidência tanto em resultados positivos quanto em resultados negativos. Portanto, o objetivo na presente pesquisa foi identificar as representações sociais de professores de escolas municipais localizadas em comunidades de baixa renda acerca da qualidade de vida dos seus alunos. Supomos que o conhecimento socialmente compartilhado da qualidade de vida dos seus alunos terá um importante papel na forma como os professores irão se posicionar frente aos mesmos.

\section{Método}

\subsection{Participantes}

Participaram da pesquisa 110 professores de escolas públicas localizadas em comunidades de baixa renda da Região Metropolitana do Rio de Janeiro. Na seleção dos participantes para este estudo foram considerados os seguintes critérios de inclusão/exclusão dos professores: atuação na educação básica da Rede Pública Municipal e Estadual; atuação em escolas localizadas em comunidades com baixo índice sócio-econômico; ambos os sexos; nenhuma restrição de faixa etária ou tempo de docência. Aqueles que correspondiam as características propostas e aceitaram participar assinaram o termo de consentimento livre e esclarecido. 
Em relação ao gênero, a amostra foi caracterizada por $81 \%$ dos sujeitos do sexo feminino e $19 \%$ do sexo masculino. Esse dado mostra uma tendência, já identificada em pesquisas anteriores, de um número maior de professoras na rede pública de ensino na região metropolitana do Rio de Janeiro (AZAMOR; NAIFF, 2009; ALMEIDA; NAIFF, 2009). O tempo de docência dos professores participantes é relativamente baixo ou em consolidação de suas carreiras com até 10 anos de prática para $48 \%$ da amostra, e 35\% estão entre 11 e 20 anos de profissão. A maioria dos docentes lecionava somente no ensino fundamental na porcentagem de 59\%, 33,6\% lecionavam no ensino médio, 4,5\% lecionavam em ambos e $2,7 \%$ dos entrevistados ocupavam cargo de direção.

Os professores participantes eram oriundos de escolas localizadas nas proximidades de aglomerados subnormais dos bairros da Ilha do Governador e Tijuca na cidade do Rio de Janeiro, Centro da cidade de Niterói, Jardim Metrópole, bairro da cidade de São João de Meriti, e Paraíso, bairro da cidade de São Gonçalo.

\subsection{Procedimentos de coleta}

Os professores participantes foram abordados através de contatos feitos diretamente em duas escolas em um primeiro momento. A partir desse contato inicial, os primeiros professores participantes apresentaram os outros e viabilizaram o acesso às outras escolas.

As entrevistas ocorreram no ambiente escolar e em reuniões em locais neutros como as associações de moradores, conforme conveniência do entrevistado.

Este estudo foi submetido e aprovado ao comitê de ética, conforme a resolução CNS/MS, no 196/96.

\subsection{Instrumentos de coleta}

Foram utilizadas uma tarefa de evocação livre com o termo indutor "qualidade de vida de seus alunos" e uma entrevista com perguntas abertas. As evocações e as categorias foram organizadas e depuradas no sentido de levantar o conteúdo discursivo e socialmente compartilhadas no grupo pesquisado. Esse procedimento respeita 0 arcabouço teórico-metodológico empregado que tem como base a Teoria das Representações Sociais e a Abordagem Estrutural. A tarefa de evocação livre nos auxilia no levantamento dos possíveis elementos do núcleo central e as perguntas semi estruturadas apóiam a confirmação dos elementos centrais e periféricos.

Nesse sentido, o material final foi analisado de duas maneiras: a) as perguntas abertas sofreram um processo de categorização na busca do sentido simbólico incorporado no conteúdo discursivo, orientado pela proposta de Bardin (2011); b) a tarefa de evocação livre foi 
analisada com auxílio do programa de computador denominado de EVOC 2003 ${ }^{\circledR}$.

A tarefa de evocação foi dividida em dois momentos, de acordo com indicação de Abric (2003). Este autor advoga pela substituição do "rang de aparição" pelo "rang de importância" como produto final da coleta de dados. Nesse sentido, primeiro foi solicitado aos sujeitos que deixassem vir o material espontâneo relacionado ao termo indutor. No segundo momento, foi pedido que hierarquizassem por grau de importância as palavras ou expressões evocadas anteriormente. Essa "técnica combinada" aproveita o material bruto nascido da associação livre e o organiza cognitivamente, permitindo uma reavaliação da ordem de evocação.

O material final foi analisado pela técnica de construção do quadro de quatro casas, e as respostas foram analisadas com o auxílio do programa de computador denominado EVOC $2003 \AA$ que combina a freqüência de evocação de cada palavra com sua ordem de evocação, buscando estabelecer o grau de saliência dos elementos da representação em cada grupo (OLIVEIRA; MARQUES; GOMES; TEIXEIRA, 2005; VERGÉS, 1994).

A organização dos dados, seguindo esta orientação, nos oferece quatro quadrantes que irão determinar o provável grau de centralidade das palavras na estrutura da representação social.

Segundo o Quadro de quatro casas identificam-se como prováveis elementos centrais da representação social os temas localizados no quadrante superior esquerdo, que foram ao mesmo tempo os mais freqüentes e hierarquizados nos primeiros lugares pelos sujeitos Por outro lado, no quadrante inferior direito, estão localizados os elementos claramente periféricos, com baixa freqüência e hierarquizados de forma secundária. Nos outros dois quadrantes, misturam-se elementos que tanto podem constituir uma espécie de "periferia próxima" ao núcleo central, quanto outros mais distantes nessa subordinação estrutural, sendo que o quadrante inferior esquerdo, composto pelos elementos que foram considerados importantes pelos sujeitos apesar de sua baixa freqüência total no corpus de análise, pode ser denominada de zona de contraste. Abric (2003) considera que este quadrante pode tanto "revelar a existência de um sub-grupo minoritário portador de uma representação diferente" (p. 64), como ser apenas composto de elementos complementares da primeira periferia.

\section{Resultados}

\subsection{Evocação livre}


$\mathrm{Na}$ perspectiva teórico-metodológica adotada pressupõe-se que os elementos considerados mais importantes pelos sujeitos, representam os prototípicos da representação social, compondo o provável núcleo central. No estudo proposto as cognições saúde, educação, alimentação e família (Quadro 1) foram às relacionadas com maior importância pelo maior número dos sujeitos conforme podemos observar no Quadro 1.

Lazer, paz e moradia aparecem na primeira periferia representando elementos de grande importância com alta freqüência ainda que em ordem de importância menor. Importante salientar que o elemento paz que apareceu na primeira periferia possui ordem de evocação limítrofe. Isso equivale a dizer, pelo caráter aproximativo do método da análise de evocações, que paz, apesar de estar localizada na periferia, pode ter uma força na representação que o alçaria ao provável núcleo central.

Na zona de contraste observamos os elementos salário, emprego, bem-estar, amor e tempo. A esses elementos foram conferidos ordens de importância significativas, mas com menor freqüência. $E$ por último, no quarto quadrante, vemos os elementos menos evocados e com menor ordem de importância: segurança, respeito, dignidade, amizade, dinheiro, esportes, cultura, alegria e felicidade.

Os dados apontam para o fato de que partindo dos elementos mais centrais para os mais periféricos encontramos, em primeiro plano, os chamados direitos sociais propostos pela Legislação Brasileira: alimentação, saúde, educação e família. Nos quadrantes posteriores vemos elementos também relacionados aos direitos sociais, porém não mais os itens básicos que dizem respeito a sobrevivência e sim àqueles que proporcionam bem estar e qualidade de vida, tais como lazer, paz, moradia, salário, bem estar, amor, tempo, segurança, respeito, esportes, cultura e alegria. 


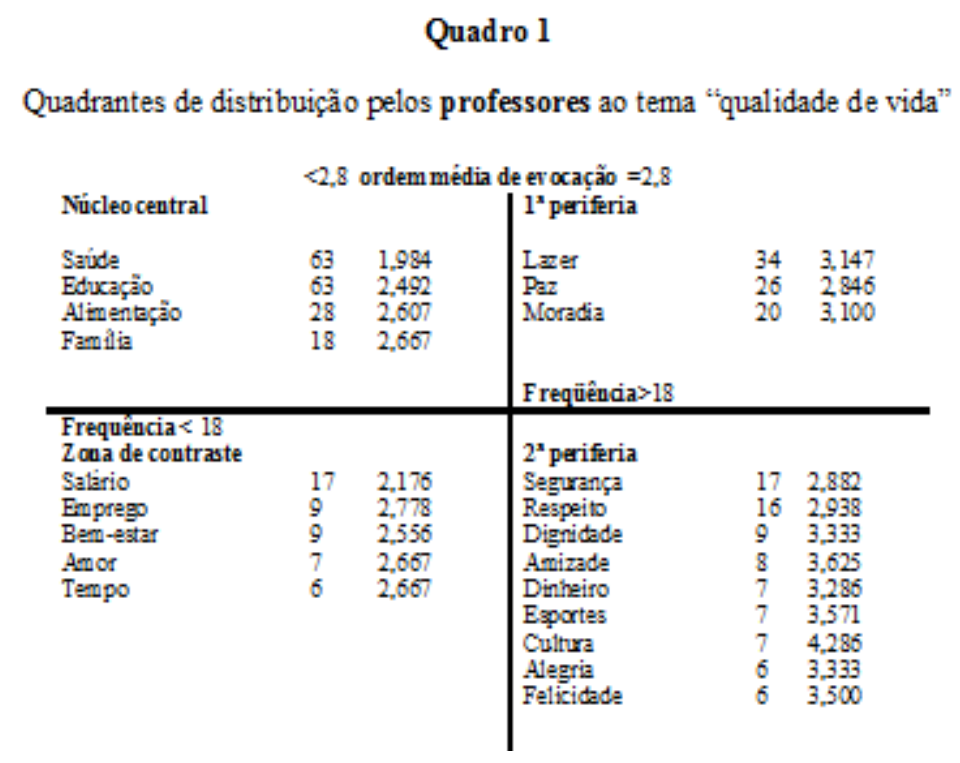

\subsection{Perguntas abertas}

Os resultados das perguntas abertas foram organizados em três grandes categorias, a saber: 1) Interferência da realidade do aluno na prática do professor; 2) Importância da escola na vida do aluno; e 3) Papel da escola no cenário social.

Em relação à Interferência da realidade do aluno na prática do professor (Tabela 1), 82,72\% admitem essa interferência e 17,27\% não a percebem $(n=110)$. Dos que observam a interferência, a participação familiar no processo educacional aparece de forma predominante tanto quando é positiva quanto quando é negativa. A relação amistosa com a família é considerada uma interferência positiva e gratificante e aparece em primeiro lugar na quantidade de registros. Em segundo lugar, aparecem questões relacionadas exatamente a vivências familiares vulneráveis e problemáticas que afetam o aluno e, consequentemente, o cotidiano escolar. Em terceiro e quarto lugares, vemos problemas de relacionamento, dificuldade de comunicação e de diálogo. A pobreza parece em 5o lugar como um fator importante de interferência, conforme os dados da Tabela 1. 
Tabela 1- Principais motivos de interferência

\begin{tabular}{lcc}
\hline CATEGORIAS & $\begin{array}{l}\text { Número Porcentagem } \\
\text { absoluto }\end{array}$ \\
\hline $\begin{array}{l}\text { Familia contribui para um bom } \\
\text { trabalho }\end{array}$ & 34 & $37,4 \%$ \\
\hline $\begin{array}{l}\text { Confusão familiar, má alimentação, } \\
\text { falta de afeto e problemas familiares } \\
\text { atrapalham o trabal ho }\end{array}$ & 17 & $18,7 \%$ \\
\hline $\begin{array}{l}\text { Falta de possibilidade de diálogo, pelas } \\
\text { diferenças culturais, necessidade de }\end{array}$ & 15 & $16,57 \%$ \\
$\begin{array}{l}\text { adaptação da escola e do professor } \\
\text { Violência, falta de respeito, falta de } \\
\text { diálogo e indisciplina }\end{array}$ & 14 & $15,4 \%$ \\
\hline Pobreza & 11 & $12 \%$ \\
\hline
\end{tabular}

Abaixo algumas falas que representam as categorias apresentadas "A dura realidade social e o abandono sofrido por alguns alunos, porque a situação de alguns me tira o sono." (Questionário 12)

"Quando a família é estruturada, a criança recebe atenção, há diálogo, recebe ajuda nas tarefas escolares, a família participa das reuniões. Tudo isso contribui para um bom trabalho." (Questionário 15)

"A vida de cada aluno tem reflexos diretos na atuação do professor. A realidade violenta das comunidades muitas vezes prejudica a relação aluno-professor." (Questionário 20).

A categoria Importância da escola na vida dos alunos foi, representada por subcategorias de uma maneira geral bastante positivas, em especial pelas oportunidades que a escola gera na vida do indivíduo no sentido de incluí-lo socialmente. De acordo com a apresentação da Tabela 2: $71 \%$ dos professores entrevistados acreditam que a escola é responsável pela formação, socialização, evolução, e por garantir um bom emprego. Essa vocação representa um estereótipo comumente relacionado à educação formal. Dados censitários (IBGE, 2000) reafirmam essa tendência e mostram que quem tem mais escolaridade está mais constantemente inserido no mercado de trabalho.

Em menor quantidade, cerca de $25 \%$ dos entrevistados, vêem motivos positivos mais gerais como ampliar a visão de mundo, ser essencial e ter relação com a qualidade de vida. Encontramos apenas dois relatos que colocam a escola como dispensável na vida dos alunos já que não é aproveitada por eles.

Os dados nos levam a discursos acerca da missão atribuída à escola que vem sendo divulgada desde o século XIX em que a educação no Brasil tinha como principal tarefa a formação do futuro cidadão apto a contribuir com o desenvolvimento de uma nação ainda em formação, como nos atesta Freire-Costa (1989). Ao longo do tempo, 
o sentido dado à escola ganha contribuições dos conhecimentos produzidos pela psicologia do desenvolvimento, da aprendizagem e da pedagogia que ampliam sua missão como um importante espaço de socialização e de aquisição dos conhecimentos culturais acumulados. Todavia, sua vocação inicial ainda perdura e se funde aos novos significados e a escola é vista como o principal caminho para a inserção social plena de um individuo socializado que pressupõe principalmente o trabalho remunerado, de preferência formal e vinculado a formação/habilidade adquirida através da educação. Portanto, essa seria o que Moscovici (1979) chama de uma representação social hegemônica que se perpetua entre os grupos sociais através do tempo e molda a forma como a sociedade se comporta frente a esse fenômeno.

Tabela 2- Impacto da escola na vida do indivíduo

\begin{tabular}{|c|c|c|}
\hline CATEGORIAS & $\begin{array}{l}\text { Número } \\
\text { absoluto }\end{array}$ & Porcentagem \\
\hline $\begin{array}{l}\text { Escol a forma, transforma, socializa, } \\
\text { ajuda na construção de um futuro } \\
\text { melhor e tem impacto na hora de } \\
\text { arrumar um emprego }\end{array}$ & 78 & $71 \%$ \\
\hline $\begin{array}{l}\text { Amplia a visão de mundo, educa, } \\
\text { abre a consciência e favorece a } \\
\text { aqui sição de novos conhecimentos }\end{array}$ & 11 & $10 \%$ \\
\hline Qualidade de vida & 8 & $7,3 \%$ \\
\hline Escola é essencial & 7 & $6,4 \%$ \\
\hline $\begin{array}{l}\text { Pouco impacto porque os alunos } \\
\text { não querem nada }\end{array}$ & 2 & $1,9 \%$ \\
\hline Não responder am & 4 & $3,6 \%$ \\
\hline
\end{tabular}

Abaixo algumas falas que representam as categorias apresentadas:

“É na escola que o indivíduo tem os primeiros ensinamentos de sua vida em grupo, onde terá o aprendizado de socialização, respeito ao próximo, respeito à diferença." (Questionário 44)

"Contribui para que as crianças e adolescentes, os jovens e adultos saibam interagir em grupo e conseqüentemente em sociedade." (Questionário 88)

"A educação faz toda a diferença para uma nação. O povo educado prospera assim a sociedade evolui." (Questionário 3)

A Escola no cenário social vista como o lugar de desenvolver um cidadão com senso crítico e com acesso ao conhecimento apareceu em $59 \%$ das entrevistas nos primeiros lugares. Em terceiro lugar, com $24,5 \%$, aparece um discurso amplamente disseminado nos dias atuais que a educação e a escola poderão resolver inúmeros 
problemas sociais como: violência, gravidez na adolescência, uso de drogas, problemas éticos, problemas morais etc, assim apresentado na Tabela 3.

Haja vista a amplitude dos problemas mencionados, faz-se cada vez mais necessária uma maior reflexão acerca da responsabilização da escola em resolver ou prevenir questões sociais extremamente complexas e multideterminadas. Esse discurso atualmente está cada vez mais incorporado nas representações sociais que a sociedade tem da escola e que nos é continuamente apresentada pelos meios de comunicação de massa, pelos discursos políticos e pelas políticas de monitoramento de resultados nas escolas que abrangem não apenas índices escolares, mas, também índices sociais relacionados a saúde, violência, drogas, trabalho, etc. Se acima afirmamos que somou-se ao discurso da escola como lugar da formação do indivíduo apto a participar de uma sociedade produtiva cunhado no século $X I X$, os conhecimentos produzidos pela psicologia e pedagogia que apresentam a escola como espaço de socialização, desenvolvimento cognitivo e da inteligência, vemos agora a inserção de novos elementos que se fundem a esses mais cristalizados em que a escola deve ser o lócus de intervenções sociais que não apenas prometa uma inserção social futura, mas execute uma inclusão social imediata.

Tabela 3- Escola no cenário social

\begin{tabular}{l|c|c}
\hline CATEGORIAS & $\begin{array}{l}\text { Números } \\
\text { absolutos }\end{array}$ & Porcentagem \\
\hline $\begin{array}{l}\text { Inserção na sociedade, dar cidadania e } \\
\text { senso crítico }\end{array}$ & 36 & $32,7 \%$ \\
\hline $\begin{array}{l}\text { Educar, dar conhecimento, desenvolver, } \\
\text { transformar, dar base }\end{array}$ & 29 & $26,3 \%$ \\
\hline $\begin{array}{l}\text { Fazer o papel da família, dar alimentação, } \\
\text { socializar, dar um perfil moral, formar } \\
\text { conceitos, formar valores, acesso a cultura }\end{array}$ & 27 & $24,5 \%$ \\
\hline $\begin{array}{l}\text { Preparar para o mercado de trabalho, } \\
\text { garantir o futuro }\end{array}$ & 7 & $6,3 \%$ \\
\hline $\begin{array}{l}\text { Espaço sem estrutura, sem objetivos e } \\
\text { competitivo }\end{array}$ & 3 & $2,7 \%$ \\
\hline Não responderam & 8 & $7,2 \%$ \\
\hline
\end{tabular}

Abaixo algumas falas que representam as categorias apresentadas:

“O elemento formador, que prepara o indivíduo para o exercício da cidadania, sendo capaz de refletir, questionar e decidir sobre questões que dizem respeito a sua vida e a sociedade". Questionário 4 
"Formar cidadãos críticos, participativos e capacitados para viverem numa sociedade extremamente competitiva." Questionário 24

"A escola no mundo atual está com a responsabilidade de fazer o papel da família, que é ensinar boas maneiras e de até mesmo sustentar onde muitas vezes é o único lugar onde se alimentam." Questionário 25

"Formar cidadãos/pessoas capacitadas para o mundo do trabalho." Questionário 89

"Prevenir o uso de drogas e a violência social." Questionário 4

\section{Discussão dos resultados e considerações finais}

Os dados mostram a educação como um direito positivado e diretamente relacionado com o conceito de qualidade de vida. Os professores apontaram em suas respostas que as representações sociais acerca da qualidade de vida de seus alunos, moradores de comunidades com múltiplas vulnerabilidades, estão mais fortemente relacionadas com os direitos básicos prescritos em nossa legislação. Esses direitos nos remetem imediatamente a noção de cidadania como: saúde, educação, alimentação e família, e nesse sentido, foram apontados como centrais na estrutura das representações sociais. Em uma posição importante, ainda que não central, os elementos lazer, paz e moradia aparecem compondo a periferia próxima das representações sociais que os professores tem da vida que levam seus alunos.

Minayo, Hartz e Buss (2000) nos orientam para o grau de polissemia que a noção de qualidade de vida incorpora. Por ser uma construção social se baseia no contexto histórico, cultural e social em que está inserida. Portanto, pressupomos que os indivíduos de uma maneira geral e o professor nessa pesquisa em particular, ao pensar qualidade de vida moldou o conceito a partir dos elementos que dispunha e que foram socialmente construídos. Vale lembrar, entretanto, que não foi pedido aos participantes que falassem do fenômeno "qualidade de vida" de forma isolada. O exercício pressupôs fundir a idéia de "qualidade de vida" e o grupo social "alunos de escolas públicas localizadas nas favelas". Em casos assim, a concepção de qualidade de vida pode sofrer variações dependendo das representações sociais que se tem do grupo social aludido, provocando uma remodelagem no conceito. De acordo com os dados apresentados, os professores enumeraram elementos percebidos como essenciais e de acesso vulnerável no cotidiano de seus alunos. 
As pesquisas que subsidiam políticas públicas e que usam índices como o IDH (Índice de Desenvolvimento Humano) e o ICV (Índice de Condições de Vida), criados pelo Programa das Nações Unidas para o Desenvolvimento- PNUD e usados para avaliar os níveis de qualidade de vida de uma população, acentuam a falta ou vulnerabilidade no acesso aos itens básicos pelas populações mais empobrecidas. Como esses ainda são os únicos índices avaliados, impregnamos mais fortemente nossas representações sociais de informações sobre o que falta objetivamente na vida dos mais pobres. Nesse sentido, Devide (2002) e Naiff (2005) apontam a deficiência desses medidores para se entender de modo amplo a qualidade de vida que uma população experimenta de fato e que está subordinada não somente a indicadores objetivos, mas, também a uma vivência subjetiva e mediada socialmente.

As necessidades básicas de sobrevivência relacionadas por Januzzi (2002) ou os itens que ocupam a terceira via dos direitos de um cidadão propostos por Marshall (1967), que advoga pelos direitos que garantam a dignidade humana, elevam a idéia de qualidade de vida a um aspecto primordial na vida social de um indivíduo. Targino (1991) argumenta que o direito a educação afeta o status da cidadania, portanto a noção de qualidade de vida sofre interferências de fatores como escolaridade. As representações sociais dos professores acompanharam as percepções usuais acerca da noção de qualidade de vida, mas foram influenciadas pelas representações que existem sobre a parcela mais pobre da população e, provavelmente, pela vivência que esse professor tem com seu aluno no cotidiano.

No contexto da pobreza, a educação ganha outros significados. A escolaridade aparece nos dados estatísticos com uma relação diretamente proporcional a melhoria nas condições de vida (IBGE, 2000), o que nos leva a supor que estar na escola aprendendo, é de fato, uma possibilidade de mudança nas perspectivas de inserção no mercado de trabalho. Nesse sentido, não foi surpresa os professores pesquisados atribuírem em suas representações sociais, quando analisados os dados da entrevista, uma importância essencial a educação tanto no desenvolvimento pessoal quanto social do aluno, e perceberem que o papel da escola não se limita a transmissão de conhecimentos teóricos formais. A escola é, para os professores, responsável também pela formação, socialização e pela inserção no mercado de trabalho, além de desenvolver o cidadão crítico. A ação da escola é diretamente afetada pela interferência positiva ou negativa da realidade do aluno que se manifesta principalmente de duas formas: pela família e pelo comportamento. Essas são as duas vias de acesso da realidade do aluno à escola de acordo com os dados.

$\mathrm{Na}$ falta da escolarização e, consequentemente, de uma inserção no mercado de trabalho de forma consistente veremos o que Martins 
(1997) chama de "nova desigualdade" que separa economicamente, mas aproxima ideologicamente, ampliando o sentimento de desigualdade. Essa situação afeta gerações que terão dificuldade de manter uma renda estável (SINGER, 1998; GOES DE OLIVEIRA, 1997; VÉRAS, 1999; GOMES; PEREIRA, 2005).O abismo econômico e social provoca a formação de preconceitos e estranhamentos entre os grupos sociais diferentes. (ARRUDA, 1998; JODELET, 1999).

Os resultados no geral apontam para o fato de que os professores estão vendo em seus alunos pessoas carentes de itens básicos de sobrevivência e, portanto, do que seria básico em qualquer definição de qualidade de vida. E que estão atribuindo grande importância ao papel da escola na reversão desse quadro no grupo social do qual o aluno é oriundo.

A guisa de conclusão, circulam socialmente representações sociais sobre qualidade de vida que incorporam tanto conceitos de cidadania, quais sejam, os direitos civis, políticos e sociais, quanto tudo aquilo considerado bom e prazeroso em nossa sociedade. Essas mesmas representações sociais sobre qualidade de vida, por conseguinte, sofrerão as variações vinculadas principalmente ao grupo social referente. Em outras palavras, quanto mais satisfeito um grupo social em suas necessidades mais básicas, mais elementos sutis comporão a sua idéia de qualidade de vida. Não que os elementos mais básicos sejam dispensáveis, mas por serem pressupostos não precisam ser anunciados e dão lugar a outros aspectos como itens de luxo e conforto. Por outro lado, indivíduos menos favorecidos economicamente precisam ser contemplados no básico e isso inibe o aparecimento de itens considerados "supérfluos" ou extras. Por esse argumento não seria estranho encontrar nas representações sociais sobre qualidade de vida de pessoas ricas itens como viagens ao exterior, iates, carros de luxo, etc. Usando da mesma lógica na leitura dos dados dos participantes é coerente ver que os professores percebem seus alunos, moradores de comunidades de baixa renda, como necessitados e carentes de itens básicos de vida. Acoplado a isso, vemos também o professor atribuindo à escola a missão de socializar e preparar para o mundo.

A reflexão que fica é: De que forma a visão da escola multicompetente e responsável por uma missão cada vez mais ampliada; o aluno visto como vulnerável em suas necessidades e a família como uma parceira em potencial mais ainda distanciada pode facilitar ou dificultar as relações entre professores e alunos no cotidiano cada vez mais conturbado das escolas públicas brasileiras? Existem certamente atuações de outras instâncias que são importantes nesse cenário e que devem compor com a escola e a família para garantir uma qualidade de vida de fato e uma vivência da cidadania aos grupos sociais mais pobres. 


\section{Referências}

ABRAMOWAY, M. Escola e violência. Brasília: UNESCO/UCB, 2003 $A B R I C$, J. C. Les reprèsentations sociales: aspects theòriques. In: J.C, $A B R I C$ (Ed.). Pratiques sociales et reprèsentations. Paris: Presses Universitaires de France, 1994, p.11-35.

La recherche du noyau central et la zone muette des représentations sociales. In: J. C. ABRIC (Ed.). Méthodes d'étude des représentations sociales. Paris: Érès, 2003, p. 59-80.

ALVES-MAZZOTI, A. Representações sociais e educação: a qualidade da pesquisa como meta-política. In: D. C. OLIVEIRA \& P. H. CAMPOS (Orgs.). Representações sociais: uma teoria sem fronteiras. Rio de Janeiro: Museu da República, 2005, p.141-150.

ALBURQUERQUE, L. G.; FRANÇA, A. C. L. Estratégias de recursos humanos e gestão da qualidade de vida no trabalho: o stress e a expansão do conceito de qualidade de vida. Revista de Administração , São Paulo, v. 33, n. 2, p. 40-51, 1998.

ALMEIDA, S.; NAIFF, L. A. M. As representações sociais dos professores do município de Mendes acerca do processo de "inclusão educacional". 2009. 235 f Dissertação de mestrado (Mestrado em Psicologia Social). Universidade Salgado de Oliveira. Programa de pós-graduação stricto sensu em psicologia, 2009.

ARRUDA, A. Representando a alteridade. Petrópolis: Vozes, 1998.

AZAMOR, C.; NAIFF, L. A. M. Representações sociais da avaliação da aprendizagem em professores do ensino público fundamental de Niterói. Revista Brasileira de Estudos Pedagógicos, Brasília, DF v. 90, p. 650-672, 2009.

BARDIN, L. Análise de conteúdo: edição revista e ampliada. São Paulo: Edições 70, 2011.

BARROS, V. A.; SALES, M. M.; \& NOGUEIRA, M. L. M. Exclusão, favela e vergonha: uma interrogação ao trabalho. In: I. B. GOULART (Org.). Psicologia organizacional e do trabalho: teoria, pesquisa e temas Correlatos. São Paulo: Casa do Psicólogo, 2007, p. 65-87.

BRASIL. Constituição 1988: Texto Constitucional de 5 de outubro de 1988. Brasília; Ed. Atual. Senado Federal, Subsecretaria de Edições técnicas, 1988, 336p.

CENTRAL BRASILEIRA DE NOTÍCIAS. Déficit de professores na rede pública é de 300 mil profissionais. Editorial País. Disponível em: <http://www.cbn. globoradio.globo.com/editoriais/pais/2011/12/29. ht $m>$. Acesso em 03/01/2012

DEMO, P. Política social, educação e cidadania. Campinas: Papirus, 2007. 
DEVIDE, F. P. Educação física, qualidade de vida e saúde: intersecção e reflexões sobre a intervenção. Revista Movimento, Porto Alegre v. 8, n.2, p.77-84, 2002.

FREI RE-COSTA, J. Ordem médica e norma familiar. 3. a edição. Rio de Janeiro: Ed. Graal, 1989.

FREIRE, P. Pedagogia da autonomia: saberes necessários a prática educativa. São Paulo: Paz e Terra, 1992.

FERREIRA, A. B. H. Novo dicionário da língua portuguesa. São Paulo: Editora Positivo, 2009.

GONÇALVES, S. M. M. Mas, afinal, o que é felicidade? Ou quão importantes são as relações interpessoais para a concepção de felicidade em adolescentes. 2006. 356f Tese de doutorado (Doutorado em Psicologia). Programa de pós-graduação em psicologia da UFRJ, 2006.

GOMES, M. A.; PEREIRA, M. L. D. Família em situação de vulnerabilidade social: uma questão de políticas públicas. Ciência e Saúde Coletiva, Rio de janeiro v. 10, n. 2, p.357-363, 2005.

GOES DE OLIVEIRA, J. L. Exclusão social: questões conceituais e doutrinárias. O Social em Questão, Rio de Janeiro, v.2, n.2, p. 1528, 1997.

INSTITUTO BRASILEIRO DE GEOGRAFIA E ESTATÍSTICA - IBGE (2000). Censo demográfico, Brasília, DF, 2000.

JANUZZI, M. Repensando a prática de uso de indicadores sociais na formulação e avaliação de políticas municipais. In: T. KEINERT \& A. P. KARRUZ (Orgs.). Qualidade de vida, observatórios, experiências e metodologias. São Paulo: Anablume/FAPESP, 2002, p.53-71.

J ODELET, D. Os processos psicossociais da Exclusão. In: B. SAWAIA (Org.). As artimanhas da exclusão. Petrópolis: Vozes, 1999, p. 5366.

Representações sociais: um domínio em expansão. In: D. JODELET (Org.). As representações sociais. Rio de Janeiro: Ed. UERJ, 2001, p. 17-44.

MARSHALL, T. H. Cidadania, classe social e status. Rio de Janeiro: Zahar, 1967.

MINAYO, M. C.; HARTZ, Z. M.; BUSS, P. M. Qualidade de vida e saúde: um debate necessário. Ciência e Saúde Coletiva, Rio de Janeiro, v. 5, n. 1, p. 7-18, 2000.

MARTINS, J. S. Exclusão social e a nova desigualdade. São Paulo: Paulus Editora, 1997.

MOSCOVICl, S. EI Psicoanálisis: su imagem y su público. Buenos Aires: Editorial Huemul, 1979.

. Representações sociais: investigações em psicologia social. Petrópolis: Vozes, 2003.

NAIFF, L. A. M.; NAIFF, D. G. M. A favela e seus moradores: culpados ou vítimas? Representações sociais em tempos de violência. Estudos 
e Pesquisas em Psicologia, Rio de janeiro, v. 5, n.2, p.107-119, 2005.

De mãe para filha: a transmissão Intergeracional da exclusão social. 2005. 280f. Tese (Doutorado em psicologia). Programa de Pós - graduação stricto sensu em Psicologia Universidade do Estado do Rio de Janeiro. Rio de Janeiro, 2005.

SÁ, C. P. "Preciso estudar para ser alguém": Memória e representações sociais da educação escolar. Cadernos de Psicologia e Educação: Paidéia, Ribeirão Preto, v. 18, série 39, p. 125-138, 2008.

- NAIFF, D. G. M. Educação de jovens e adultos em uma análise psicossocial: representações e práticas sociais. Psicologia e Sociedade, São Paulo, v. 20, p. 402-407, 2008.

SOARES, A. B.; NAIFF, D. G. M.; AZAMOR, C.R.; ALMEIDA,

S. A.; SOUTO, C. S. Ensino público e privado: comparando representações sociais de professores sobre suas habilidades. Psicologia em Pesquisa, Juiz de Fora, v. 4, n. 1, p. 57-64, 2010. OLIVEIRA, D. C.; MARQUES, S. C.; GOMES, A. M. T.; TEIXEIRA, M. C. T. V. Análise das evocações livres: uma técnica de análise estrutural das representações sociais. In: A. S. P. MOREIRA; B. V. CAMARGO; J. C. JESUÍNO; S. M. NÓBREGA (Orgs.). Perspectivas teóricometodológicas em representações sociais. João Pessoa: Editora UFPB, 2005. p. 573-603.

ORGANIZATION MUNDIALE DE LA SANTÉ -OMS - Grupo calidad de vida. Qué calidad de vida? Foro Mundial de la Salud, São Paulo, v. 17, p. 385-387, 1996.

PEREIRA, L. A. S. As recentes políticas públicas nas favelas cariocas: mais do mesmo? Revista Geográfica de América Central, Número especial, Heredia, Costa Rica, p. 1-13, 2011.

POPKEWITZ, T; LINDBLAD, S. Estatísticas educacionais como um sistema de razão: relações entre governo da educação e inclusão e exclusão sociais. Educação \& Sociedade, Campinas, v. 75, p. 111148, 2001.

PREFEITURA DO RIO DE J ANEIRO. Moradia, segregação, desigualdade e sustentabilidade urbana. Rio Estudos. In: Rio Estudos. № 31. Disponível em <http://www.armazemdosdados.rj.gov.br> Acesso em 20 de novembro de 2004.

ROCHA, S. S. L.; FELL, V. E. A. Qualidade de vida no trabalho docente em enfermagem. Revista Latino Americana de Enfermagem, Ribeirão Preto, v.12, n.1, p. 28-35, 2004.

SÁ, C. P. de. Núcleo central das representações sociais. Petrópolis, RJ: Vozes, 1996.

. Construção do objeto de pesquisa em representações sociais. Rio de Janeiro: EdUERJ, 1998.

SINGER, P. Globalização e desemprego: diagnóstico e alternativas. São Paulo: Contexto, 1998. 
TARGINO, M. G. Biblioteconomia, informação e cidadania. Revista da Escola de Biblioteconomia da UFMG, cidade, Belo Horizonte, v.20, n. 2, p. 149 - 160, 1991.

TOLEDO, J. R. Os miseráveis são 25.000.000. Folha de São Paulo, São Paulo, 26 de setembro. Caderno especial: O Mapa da Exclusão, 1998, p. 1-3.

TWENGE, J.; KING, L. A good life is a personal life relationship fulfillment and work fulfillment in judgments of life quality. Journal of research in personality, New York, v. 39, p. 336-353, 2005.

VELLOSO, C. M. S. Dos direitos sociais na constituição do Brasil. Texto básico de palestra proferida em Madri, Espanha, na Universidade Carlos III, em 10.3.2003. Disponível em: <http://www. ufrnet.br/ufrnetnovo/>, acesso em 18 de maio de 2008 VÉRAS, M. Exclusão Social - um problema brasileiro de 500 anos. In: B. SAWAIA (Org). As artimanhas da exclusão. Petrópolis: Vozes, 1999, p. 27-52.

VERGĖS, P. Approche du noyau central: propriétés quantitatives et structurales. In: $\mathrm{CH}$. GUIMELLI (Ed.). Structures et transformations des représentations sociales. Lausane. Delachaux et Niestlé, 1994, p. 233-253.

WILSON, T.; ALVES-MAZZOTI, A. Relação entre representações sociais de "fracasso escolar" de professores do ensino fundamental e sua prática docente. Educação e cultura Contemporânea, Rio de Janeiro, v. I, n. I, 2004

WORLD HEALTH ORGANIZATION QUALITY OF LIFE. Whoqol. Asessment: position paper from the World Health Organization. Social Science Medicine, Exeter, v. 41, n. 10, p. 1403-1409, 1995.

\section{Endereço para correspondência}

Luciene Alves Miguez Naiff

BR 467, Km 47, Departamento de Psicologia, Mestrado em Psicologia/PPGPSI, sala 15, CEP 23890-000, Seropédica - RJ , Brasil

Endereço eletrônico: lunaiff@hotmail.com

\section{Denis Giovani Monteiro Naiff}

BR 467, Km 47, Departamento de Psicologia, Mestrado em Psicologia/PPGPSI, sala 15, CEP 23890-000, Seropédica - RJ, Brasil

Endereço eletrônico: dnaiff@ufrrj.br

\section{Alcina Maria Testa Braz}

Rua Lucio Tavares, 1045, CEP 26530-060, Centro, Nilópolis - RJ

Endereço eletrônico: alcinamaria@gmail.com

Recebido em: 07/02/2012

Reformulado em: 23/05/2013

Aceito para publicação em: 09/06/2013

Acompanhamento do processo editorial: Deise Mancebo 
Luciene Alves Miguez Naiff, Denis Giovani Monteiro Naiff, Alcina Maria Testa Braz Representações sociais de professores sobre a qualidade de vida dos seus alunos

\section{Notas}

* Professora adjunta da UFRRJ, Rio de Janeiro, Brasil. Coordenadora do mestrado em Psicolgoia da UFRRJ, bolsista de produtividade CNPq, Jovem Cientista do Nosso estado FAPERJ, doutora em Psicologia social pela UERJ .

**Professor adjunto da UFRRJ, Rio de Janeiro, Brasil. Diretor do Instituto de Educação da UFRRJ, doutor em Psicologia social pela UERJ .

*** Professora da UNIVERSO, Rio de Janeiro, Brasil. Professora do Instituto Federal de Educação, ciência e tecnologia do Rio de Janeiro, Diretora da Unidade Nilópolis, doutora em Educação pela UFRJ 